\title{
What to do when you don't trust your doctor
}

\author{
DAVID J D FARROW, D J PEREIRA GRAY, J A MUIR GRAY;, DAVID HOMESHAW
}

We were sent the letter printed below by an agony aunt on a woman's magazine. She asked how we would advise the author. We asked two general practitioners, a community physician, and a family practitioner committee administrator what they would advise. Their answers are printed below.

\section{Dear Agony Aunt,}

I should appreciate your advice. Two years ago I moved here to Dinkyville from London. In London there were a number of doctors unconnected with one another, and if you were dissatisfied with your treatment you could without too much difficulty change your doctor. Here there is only a "health centre" manned by four doctors. So there is no choice-you either go there or you don't get any medical treatment.

I am sorry to have to say that I am not alone in having a lack of confidence in the various doctors in the health centre-and several people have told me that they never go there if they can possibly help it and have given me instances of unsatisfactory treatment they have received. From my own experience, had I taken the advice of one doctor there I might have lost the sight of my left eye. Not satisfied

\footnotetext{
Hawkhurst, Kent TN18 4EX

DAVID J D FARROW, MB, DRCOG, general practitioner

9 Marlborough Road, Exeter EX2 4TJ

D J PEREIRA GRAY, OBE, FRCGP, general practitioner and professor of general practice
}

Community Health Offices, Radcliffe Infirmary, Oxford OX2 6HE

J A MUIR GRAY, MRCGP, FFCM, community physician

Kent Family Practitioner Committee, Maidstone, Kent ME14 1QH DAVID HOMESHAW, BSC, LHSM, administrator with his diagnosis that there was "nothing wrong," I took myself to the eye casualty department of Ivorytown University Hospital, where I was given immediate laser treatment for a tear in the retina.

Now I again disagree with a diagnosis and would like a second opinion-but where do I get this? Certainly not from one of the other three doctors in the centre, who would only "gang up" with their colleague. No other National Health Service doctor would take me on, as I would not be in his area. I would willingly go to a private doctor, but the local health authority have only NHS doctors on their list. So how do I find a doctor that takes private patients? Can you help me? I am fairly desperate and very worried.

\section{Dr Farrow replies:}

I would advise your fairly "desperate and very worried" woman correspondent that perhaps her predicament would be resolved happily if she were to discuss it as soon as possible with the practice. Initial contact could even be made by a friend (with her consent) with any member of the practice. I think she would be surprised to learn how upset and concerned they would be on her behalf and very willing to arrange for a specialist opinion. The practice will have a contingency plan to deal with this apparent situation of "no choice for patients"-that is, change doctors within the partnership or recommend her to a private doctor, for example. They will probably be able to take her on as a private patient should she wish because although "the local health authority have only NHS doctors on their list" this does not preclude NHS doctors having private patients.

Only when the patient has got her worries off her chest will she be able to appreciate the willingness of the practice to help her and dispel any idea of doctors ganging up with each other. It would be unwise for written or impatient defensive statements to be mademuch better to listen and hear the matter out. The patient may realise the "accused" doctor had no way of detecting a retinal tear and be prepared to end the matter with an explanation and apology.

The ability to handle these seemingly impossible problems is the very essence and challenge of family doctoring. Resolving them 
cements a foundation of mutual respect between patients and their family doctor.

As the practice and the patient may eventually have to live with each other the practice must grasp the initiative and hear the patient out.

\section{Professor Pereira Gray replies:}

I was very sorry to read your letter and to learn that you are so unhappy with your general practitioner. You say that you have lost confidence in him. Before trying to find another one, however, you might try going back to him and discussing your feelings openly with him. He should be given a chance to put his point of view. If he made a serious mistake he ought to know about it-most doctors would rather hear from a dissatisfied patient direct than from other people. Doctors and patients have much to learn from each other, and just as your doctor has a responsibility to help and advise you so you have a responsibility to help and advise him. Your intervention might help other patients in the future.

You suggest that if you go to one of the other doctors then all of them will "gang up on you." This is not necessarily true. In many small towns doctors are prepared to accept transfers from partners, particularly if there is little choice in the area. Choice of doctor is very personal and most general practitioners understand this. Moreover, I do not think that it was fair to write off your doctor's partners without good evidence. Bad news travels fast, and people who have had problems always talk about them far more than the greater number of people who are satisfied with their doctors.

You say that no other NHS doctor would take you on as you would not be in his area. This is not necessarily the case. Although choice of doctors in country areas is naturally limited, as indeed is choice of all services, some doctors accept patients at much greater distances than doctors in big cities. It is worth checking with your local family practitioner committee, whose address you can find in the telephone book, to see if any other NHS doctors cover your area. If not, you can look for a private doctor elsewhere.

If all else fails, your family practitioner committee administrator has the power to "allocate" you to a doctor. It is far better to try and arrange a change for yourself, however. I hope that you are able to do this. Don't forget that if you are worried about a diagnosis you can always ask for a second opinion. It is not fair to assume that your doctor would not make a referral unless you ask him to do this.

\section{Dr Muir Gray replies:}

I am sorry to hear of the difficulties you are having with your local health centre. So far as your specific request for information about private care is concerned, I think that the only step you can take is to write to one of the main provident societies and say to them that you would like to become a member of a private health insurance scheme. Joining such a scheme, however, will not solve all your problems, in part because some consultants prefer to have a link with a local general practitioner when seeing patients, in part because few of the provident associations provide general practice cover, although they are good sources of advice on specific problems. Thus even joining a provident association and taking out health insurance would still leave you with the need for support from a general practitioner from time to time.

You could keep your fingers crossed and hope that when problems arise you will obtain satisfactory service or you could try to meet one of the doctors in the health centre, preferably the doctor in whom you have most trust, and explain to him or her the difficulties that you have had with the service in the past. So far as this particular problem is concerned, you could go to see one of the doctors and simply say that you would like a second opinion because you are anxious. You may find it helpful to write to the general practitioner beforehand as it is sometimes easier to set things out on paper rather than simply to say them. Such an approach might improve your confidence in the practice as a whole and thus reduce your need to seek private care.
I am sorry that there is nothing further I can do to help you; you might find it useful to talk this over with the local community health council if you are unable to resolve it in the manner that $I$ have suggested.

\section{Mr Homeshaw replies:}

You are right-without confidence in your family doctor you will not make the best use of the NHS, and occasionally emergencies may need to go direct to a hospital. Generally, however, your family doctor will give you appropriate treatment and only if necessary refer you to hospital. Unfortunately, your recent experience has made you doubt this system and look for private treatment.

Expectation is the underlying problem. Like most marriages a good patient-family doctor relationship has to be worked at by both parties so that the relationship is strong enough to cope with crises and different points of view. Thus your first reaction when you have doubts about a doctor's treatment should be to explain this to him rather than change doctor.

Your doctor should respect this approach, as it will give him the opportunity to double check and ascertain if your condition has changed. He needs his skills and also information from you to give you a good service. This may be easier in a small town like Dinkyville than in London, as people move less often and doctors tend to know their patients better.

If your doctor cannot resolve your current concern try to register with another doctor in Dinkyville. Accessibility is important, and doctors understand that patients may need to change doctors within the same practice or health centre. Ask to see the other doctors, explain your situation, and make up your own mind.

If you should be unable to register with another doctor contact your local family practitioner committee. They will advise you whether other doctors accept patients in Dinkyville, and if required will assign you to a doctor's list, although not necessarily to the doctor of your choice. Similarly, patients' complaints about family doctors are considered by the family practitioner committee.

\section{YEARS AGO}

A curious outbreak of convulsionist mania, analogous to those which occurred from time to time during the Middle Ages, is reported to have shown itself at Agosta, in the province of Rome. For some weeks past the country people have been labouring under the delusion that the district is under the immediate government of the Evil One, and before retiring to rest they carefully place on the threshold the broom and the salt, which are credited with the power of keeping off evil spirits. Many of the younger women have epileptiform attacks, during which they utter piercing shrieks, and are violently convulsed. So serious had the condition of things become, that the syndic of Agosta found it necessary to inform the Prefect, who sent detachments of soldiers into the district in order to calm the apprehensions of the inhabitants. The contrast between this strictly physical way of dealing with the disease and the more imposing but less effectual religious ceremonies formerly employed must be interesting to historical students. As a natural consequence of this condition of mental perturbation, the country is overrun with quacks who claim to possess the only infallible remedy for the seizures. One of these nostrums, the vendor of which was making a rich harvest from its sale, was found on analysis to consist of earth, snuff, and borax. Three medical men who were commissioned to investigate the cause and nature of this extraordinary affection, came to the conclusion that it was an epidemic of hysteria. They examined a number of the sufferers, mostly young women, some of whom were alleged to have vomited nails, horseshoes, and other equally indigestible substances, while others barked like dogs. Several of them were removed to Rome for treatment in the hospitals there, and measures have been taken to check the spread of the mischief. In a milder degree, this contagious form of hysteria is not infrequent, especially in places where ignorance and superstition favour manifestations of nervous disorder. The worst excesses of popular outbreaks, like the French Revolution, have been attributed to similar influences, and with every appearance of justice. (British Medical Fourmal 1887;ii:94.) 